This is a self-archiving document (manuscript version):

The assessment of market power of hub airports

By: Polk, Andreas; Bilotkach, Volodymyr

Published in: Transport Policy

Volume 29, September 2013, Pages 29-37 (Please be aware: Page numbering in this manuscript can be different to published version!)

Publisher: Elsevier | Year: 2013

DOI: 10.1016/j.tranpol.2013.03.004

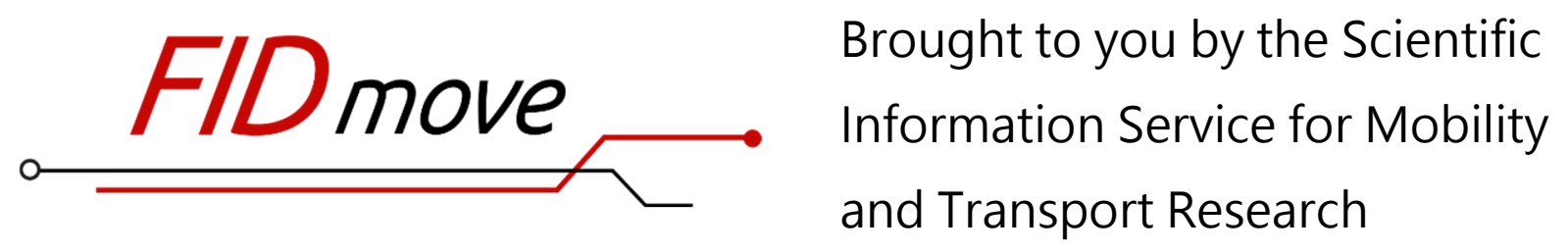

Fachinformationsdienst Mobilitäts- und Verkehrsforschung

Website: www.fid-move.de

Repository: publish.fid-move.de

Contact: publish@fid-move.de

(C) 2021. This manuscript version is made available under the CC-BYNC-ND 4.0 license.

http://creativecommons.org/licenses/by-nc-nd/4.0/ 


\title{
The assessment of market power of hub airports
}

\author{
Andreas Polk ${ }^{\mathrm{b}, *}$, Volodymyr Bilotkach ${ }^{\mathrm{a}}$ \\ a Newcastle University Business School, 5 Barrack Road, Newcastle upon Tyne, NE1 4SE, United Kingdom \\ ${ }^{\mathrm{b}}$ Berlin School of Economics and Law, Badensche Str. 50-52, 10825 Berlin, Germany
}

A B S T R A C T

Airport regulation regimes are under revision in many countries. The decision about the extent of airport regulation is based on an economic analysis of market power, which is done in two steps. The first step involves defining the relevant markets the airport is operating on. This in turn is based on an economic analysis of the particular circumstances of the airport, and must be compatible with competition law. The second step consists of the evaluation of the airport's competitive position in all identified markets. Due to industry particularities, many diverse issues must be taken into account in this process, such as questions of upstream and downstream market interaction, airport congestion, peak-load pricing, or offsetting bargaining power. Many of these questions have been theoretically analyzed in the industrial organization literature, but have only rarely been applied in practical competition analysis with respect to airports. This paper builds a bridge between the theoretical insights and their practical application to airport regulation policy. We derive the principles for a sound economic analysis of the market power of airports, given the time and data constraints encountered in practice by the regulatory authorities and other involved parties, and propose a general framework for the analysis of market power of airports. We focus on hub airports, as the analysis of these gateways covers all the relevant issues, including countervailing power of the hub operator.
Keywords:

Regulation policy Competition policy Airports Aviation

\section{Introduction}

Hub airports occupy a key place in the global transport infrastructure. They handle a significant share of passenger air traffic, tend to be prone to congestion, and typically have features of local monopolies. As a result, large hub airports are usually subject to economic regulation. There is no uniform approach to the economic regulation, with the regimes differing across countries and jurisdictions. However, it is hard to find any large hub airport which is not subject to any kind of economic regulation at all. ${ }^{1}$ Regulatory regimes often foresee a recurring review process, which aims at identifying possible needs to adjust regulation. As regulation should only be imposed on markets where competition is not feasible, identifying the relevant markets and the extent of potential market power becomes an important issue. This is a crucial step in any review process, and must be done on a case by case basis. However, we actually find few cases where such an exercise has been implemented in practice. $^{2}$

The assessment of market power has to take two things into account. First, it has to consider the economic circumstances at the particular airport, rather than rely on general economic ideas without evaluating whether they are suitable for this particular entity. Second, it has to take account of the institutional framework which governs the airport. In addition to the general competition

\footnotetext{
* Corresponding author. Tel.: +493030877 1162

E-mail addresses: polk@hwr-berlin.de (A. Polk),

Volodymyr.Bilotkach@newcastle.ac.uk (V. Bilotkach).
}

Published version can be found here: http://dx.doi.org/10.1016/j.tranpol.2013.03.004

\footnotetext{
${ }^{1}$ In Europe, the recently adopted regulation on airport charges provides general principles and leaves concrete implementation to the discretion of the member states. European countries follow individual approaches towards airport regulation, with rather basic ex ante approval procedures of prices in some countries (like Spain) or more elaborate price-cap or rate-of-return regulation approaches in others (i.e. Great Britain). Moreover, approaches might vary even within a country, as for instance in Germany (Marques and Brochado, 2008; European Parliament, 2009; Backers et al., 2010; Bel and Fageda, 2010; Gillen, 2011). In the US, several acts by the Department of Transportation and the Federal Aviation Administration provide general principles on the setting of airport charges, such as reasonableness and costorientation. Further specifics are worked out in bilateral agreements between the airports and the airlines. Approaches to
}

(footnote continued)

establishing the airport charges differ mostly according to questions on which market participant takes the risks arising from possible demand or supply shocks (Van Dender, 2007; Gillen, 2011; Graham, 2004). Australia shifted the regulatory regime to a relatively light-handed approach, which relies on bilateral negotiations between airports and airlines, combined with different kind of threats (i.e. arbitration, re-regulation) in case it turns out that negotiations fail or the system does not work well (Forsyth, 2004; Gillen, 2011).

${ }^{2}$ Müller et al. (2010) assess the market power of Amsterdam Airport Shiphol; Competition Commission (2009) and Civil Aviation Authority (2010) discuss it fo UK-airports. In Beckers et al. (2010, chapter 4) we find a brief discussion of the market power of German airports, and a recent report by Copenhagen Economics (2012) analyzes competition in the European airport markets. 
policy considerations, the latter may include national regulatory guidelines or strategies for development of the aviation infrastructure in a particular country.

Our study develops a framework for the assessment of market power of airports, which takes institutional aspects into account. We derive a set of economic principles, which serve as a basis for the assessment of market power. Our aim is to build a bridge between the theoretical analysis of airport related topics in the industrial organization literature, and their application to policy making in practice, as well as between the theory-biased economic way of thinking and the law-based institutional approach in the regulatory decision-making process.

This contribution starts with preliminary remarks on airport specific topics in Section 2. Section 3 covers the institutional context of the decision-making process, which is market definition according to the particular competition law rules. Section 4 analyzes airport-specific factors which affect market power. Section 5 proposes a general framework for the analysis of market power. Finally, Section 6 covers the effects of market power with a focus on price-setting and bilateral bargaining.

\section{Conceptual preliminaries}

\subsection{Upstream and downstream market interaction}

Airports serve the airlines offering cargo and passenger transportation services to end-customers. Hence, airports face derived demand, which comes from the downstream transportation markets. Upstream, the airport offers infrastructure services to the airlines (and it usually also addresses end-customers directly, for instance by offering parking facilities at the airport). The assessment of market power of airports has to take these interdependencies into account. It has to contain an analysis of the economic interaction between the downstream transportation markets, and analyze the impact of this interaction on the demand for airport services upstream. Analysis of the market power of hub airports is complicated by the presence of a large customer-an airline using the airport as a key node in its network. This situation creates an interesting inter-dependence between the airline and the airport: while the airport may be the only provider of infrastructure the carrier requires to operate its hub, the airline can also potentially wield countervailing power.

Whereas studies on competition in the downstream transportation markets are numerous, the literature on the upstream airport markets is less extensive. It may be tempting to transfer the knowledge and case law of the downstream transportation markets one by one to the analysis of the upstream airport markets, but this misconception will very likely lead to wrong implications. For instance, the elasticity of demand downstream affects the airport markets upstream, but it is not identical to the demand elasticity of airports vis-a-vis the airlines. Or take the definition of the relevant product markets as a second example. In the downstream transportation markets it is often appropriate to delineate the markets depending on the travelers' time sensitivity. But this does not necessarily translate into different airport markets upstream, for instance if the airport is not able to pricediscriminate between different customer groups.

As a consequence, care must be taken concerning the transfer of case law between the upstream and downstream markets; nevertheless, it is necessary to take these interdependencies into account. Without a solid understanding of competition in the downstream transportation markets and how it translates upstream, the assessment of the market power of airports is at best incomplete. For instance, the question of whether an airport can profitably increase airport charges depends crucially on the characteristics of the 
downstream transportation markets. If demand is inelastic downstream, it is likely that the airlines will be able to pass cost increases through to end customers, which makes the price increase likely profitable for the airport as well. In case downstream demand is elastic, the airlines' cost structure, the degree of downstream competition, and the importance of network effects determine whether the price increase would lead to a loss of demand downstream, and if this loss would be substantial enough to render the price increase unprofitable for the airport as well.

\subsection{Assessing past behavior versus forecasting the future}

The market definition and the assessment of market power rely on an analysis of the relevant economic circumstances of the specific airport under investigation. This invokes the following conceptual issue: on the one hand, the market definition and the assessment of market power should provide a profound analysis which is usually based on evidence about past behavior, as speculation about future managerial conduct and business strategies are likely to fail. ${ }^{3}$ On the other hand, what we observe in most cases is conduct under regulation, which does not necessarily reflect the true economic market incentives at play, i.e. market forces without regulation. This underscores the need for carefully constructing an appropriate counterfactual to be used when forecasting the airport's behaviour following the changes in regulation.

Strategies for coping with this issue are case-specific. In many cases, the task of assessing market power (which includes preceding market definition) may be a step in an investigation which aims at adjusting a given regulation marginally. The past and observable behavior of the regulated entity may serve as an appropriate basis for analysis in this case. It is verifiable, less speculative, and serves the purpose of the exercise. In contrast, if the purpose of the assessment is to determine the appropriateness of a complete change of the regulation regime (for instance if the airport should be freed from regulation), it appears suitable to direct the analysis towards the assessment of a likely behavior of an unregulated entity, for instance by analyzing different market scenarios. However, the reliability of forecasts about unregulated pricing behavior or bargaining processes between the airport and important carriers will likely be limited, especially if downstream transportation markets develop dynamically. Due to the risk of errors in the latter scenario and the purpose of most investigations, we believe that basing the analysis on observable behavior in the past is appropriate for the analysis of market power in many cases.

Secondly, note that effective regulation restricts the airport's ability to exert market power. Further, we are severely restricted in our ability to construct the relevant counterfactuals - i.e., forecast how an airport would act absent the regulation - as comparable non-regulated airports are hard to find in practice. If the assessment is based on the past behavior of a regulated hub airport, the results tend to be biased towards an underestimation of the 'true' market power of the entity absent the regulation. Hence, where an assessment based on the past behavior concludes that market power exists, this should not cause concern with respect to continuing economic regulation. In contrast, if the analysis concludes that market power is absent, results should be taken with caution given that it is exclusively based on evidence about past behavior under regulation. Decision makers need to be aware of this potential bias.

\footnotetext{
${ }^{3}$ This approach is usually employed in competition policy cases, where evidence of past behavior is used to assess if a merger has the potential to harm competition in the future.
} 


\section{Institutional framework: the definition of the relevant markets}

\subsection{General principles}

A necessary first step for any assessment of market power is the definition of the relevant markets with respect to products and geography. It aims at identifying sources of competitive constraints and determines the economic markets an airport is active in. It is not a pure description of the airport's services, but an analysis of the relevant substitution patterns from an economic point of view. Market definition is a necessary prerequisite for the assessment of market power, and thus not an end in itself. A broad consensus exists about the economic concepts underlying market definition, subtleties left aside. ${ }^{4}$

With respect to the definition of the relevant product markets, the analysis mainly rests on the notion of demand-side substitution. ${ }^{5}$ If the cross-price elasticities between two products are positive, customers shift demand from one good to another if the relative price structure changes. This implies that the customers consider the two products as interchangeable, and it may be appropriate to conclude that the products belong to the same market. If cross-price elasticities are close to zero, the demands for the products can be considered independent and the definition of separate markets is appropriate. The $\operatorname{SSNIP}^{6}$ or hypothetical monopolist test reflect these ideas, serving as a conceptual framework for many applications. It is an iterated procedure with the idea of broadening the market in a stepwise fashion until a hypothetical price increase for all producers turns out to be profitable. To implement these tests, one usually starts with the most narrow suitable market definition, and assumes that all producers in this market jointly increase prices by five or ten percent. If the price increase turns out to be unprofitable, consumers must have shifted their consumption towards some substitutes, which have been left out of consideration at this stage of analysis. The relevant product market is broader than initially assumed then. So one would be wise to include the closest substitutes in the next step, and repeat the procedure, now for the extended range of products and producers. In contrast, if the price increase turns out to be profitable, no further substitutes are available. Customers are unable to switch consumption towards alternatives then, and the proper market boundaries have been identified.

\footnotetext{
${ }^{4}$ A more detailed description of principles of market definition and its possible fallacies provide Motta (2004, chapter 3), Bishop and Walker (2010, chapter 4) Dobbs (2006) or the Merger Guidelines Workbook of the International Competition Network (International Competition Network, 2006). The ICN guidelines are nonbinding for the national competition authorities, but provide a broad overview about how competition authorities think about the issue of market definition. Nationally binding obligations closely related to these norms abound, i.e. the merger guidelines in the US (US Department of Justice and Federal Trade Commission, 1997) or the notification on the definition of the relevant market in the EU (European Commission, 2004). Usually, the precise definition depends on the purpose of the investigation and there is no 'universally true' market definition.

5 Supply-side substitution may play a role in market definition if other suppliers are capable of entering the market within the short time frame without significant additional investment in case of a price increase by the incumbent (Padilla, 2001). In the context of airport markets this implies that when an airport increased prices, alternative airports which are not yet present in the market could easily step in. This is unlikely to play a role in many investigations, especially where the hub airports are concerned, so we leave this aspect outside of the scope of this study.

${ }^{6}$ SSNIP $=$ Small but Significant Non-transitory Increase in Prices. Demand data or data about cross-price elasticities are seldom available in proceedings an investigations, which are usually performed under severe time constraints. This usually makes estimations for the purpose of market definition impossible in practice. Examples for econometric applications of the SSNIP-test are Brenkers and Verboven (2007), Gaynor et al. (2011), and Ivaldi and Lorincz (2011).
} 
The resulting market definition contains all goods and serving as substitutes, but not more.

The SSNIP-test is a helpful concept for the definition of the relevant markets. However, application of this concept requires clear awareness of the underlying contexts. For instance, the chosen time horizon within which substitution may occur plays a crucial role in the analysis. Demand for an airport services is nearly perfectly inelastic in the very short run, because airlines will not be able to adjust their fleet and schedules quickly. The airlines' ability to potentially adjust fleet logistics defines the appropriate time horizon for the SSNIP-test, which tends to be shorter for demand by cargo or charter airlines as compared to the network airlines. Moreover, the SSNIP-test may lead to wrong implications if the observable prices are not the competitive ones, which is known as the cellophane fallacy. This fallacy does not render the test redundant, but underscores the need to apply it with care Bishop and Walker (2010, chapter 4).

Alternative concepts have been developed to complement the idea of the SSNIP-test. Their applicability depends on the context of the investigation and the availability of data. Sometimes we may benefit from natural experiments if it is possible to observe an exogenous shock in the market, like the introduction of a ticket tax, an event like $9 / 11$, or an unforeseeable natural phenomena like the eruption of the Icelandic vulcano Eyjafjallajökull in 2010. In some cases we may benefit from insights these events generate, and the change of the price structure following the shock may indicate the degree of substitution between different products. Another alternative concept is the analysis of price patterns and price correlations. A positive price correlation of two products which is not driven by inflation or costs gives an indication towards substitution effects. Combined with other evidence, it may be appropriate to define a common market in this case.

Some issues may complicate the definition of the relevant markets, with bundling and secondary products being especially relevant for hub airport markets. If goods are usually consumed as bundles, they belong to a common market even if they are not exchangeable from a customer's point of view. If customers usually buy bundles of certain products, or if suppliers usually offer bundles at a unique price, the definition of a separate product market for each item in the bundle is irrelevant from an economic perspective and it unnecessarily complicates the assessment. In this case it is appropriate to define a common market which includes all bundled products. The same may apply for secondary products (or aftermarkets), which are goods or services purchased as a follow-up to an earlier buying decision. Examples are spare parts for aircraft given the prior purchasing decision for a particular aircraft model, or ground handling services which an airport provides. Whether it is appropriate to define a common or separate product markets in this case depends on the purpose of the investigation and on market characteristics like the available information at the time of the initial purchasing decision or the degree of competition for the provision of the secondary products.

The geographic market definition identifies the area within which customers regard different suppliers as interchangeable. For instance, regional preferences, national regulations, or the existence of transportation and transaction costs may restrict the geographic area within which trade occurs. For instance, customers of air services usually have a preference for short journeys to the airport, but may be willing to accept more distant journeys if prices differ substantially between two locations. This again may differ between different types of customers, like business or leisure travelers. Hence the market definition in the airport upstream market depends on the analysis of customer behavior downstream. Depending on the product and the type of customers, markets may be regional, national, transnational or world-wide. 


\subsection{Market definition for hub airports}

Airports are multi-product companies which offer a variety of services. The most important services are the provision of infrastructure for take-off and landing of aircraft carrying cargo and passengers, ground-handling services, the provision of central infrastructure to the airlines, rental space, or supply of parking and shopping facilities for end-customers at the airport. The degree of competition for the provision of these services differs. For instance, competition tends to be more intense in the market for the provision of parking facilities or rental space compared to the provision of infrastructure to airlines. Hence it is not helpful to assume a single 'airport market'. ${ }^{7}$ If the assessment of market power rests on this notion, it is bound to have a limited meaning within the institutional framework and risks simplifying conclusions.

The definition of the relevant product markets. We propose to start the market definition exercise with an analysis of the structure of the airport charges. This is also appropriate if the airport is regulated, provided that the regulatory regime leaves discretion to price-discriminate between different types of services. If the airport is able to price-discriminate between different types of services or customers, the definition of the relevant product markets along these lines appears reasonable if customers are not able to substitute between the services in case of price changes. Price discrimination between different types of airlines (full service airlines, low-cost airlines, cargo airlines) or different types of customers which the airlines carry (such as origin-anddestination, $0 \& D$, and transfer passengers) may serve as an example. In contrast, it may also appear reasonable to define a common product market in the presence of different prices. This might be the case if price differences are driven by cost or other factors. As an example for the latter, an airport might charge different prices depending on the noise level of the aircraft in order to provide incentives to employ low noise emission aircraft and reduce negative external effects. The definition of a common product market might also be reasonable if the definition of separate markets does not help to add important insights for the purpose of the analysis.

The analysis of reaction of prices and quantities to exogenous shocks and the analysis of demand patterns as a reaction to asymmetric price changes can be helpful in defining markets. As an example, the air passenger tax introduced at Amsterdam Airport Schiphol in 2008 was exclusively levied on O\&D passengers, but not on transfer passengers. As a result, origin-destination passenger traffic decreased at the airport, whereas demand by transfer passengers was mainly left unaffected. Accordingly, services tend to be independent of each other from the airport's point of view, which gives evidence in support of separate product markets. In contrast, if arbitrage or substitution effects occurred, services likely belonged to a common product market.

Bundling plays an important role for the definition of the ground handling markets. First, ground handlers usually offer bundles for a variety of services (i.e. ground handling for passenger flights, ground handling for cargo flights), and the definition of markets for the product bundles instead of single services is appropriate. More important, the analysis has also to address if ground handling is a separate product market, or if it belongs to a common product market for the provision of infrastructure to airlines which includes ground handling. In case the airport is the

${ }^{7}$ Market definitions for airports are rare in practice. Müller et al. (2010) apply it to Amsterdam Airport Shiphol; Competition Commission (2009) and Civil Aviation Authority (2010) discuss it for UK-airports; The European commission discusses principles of market definition in European Commission (1997) and subsequent cases (European Commission, 2005, 2006). 
only provider of ground handling services at the airport, the definition of a common market is more likely. Ground handling is secondary then to the provision of infrastructure at the airport, and it is very likely that the airlines take the cost for ground handling services into account when managing the allocation of its fleet. In contrast, if the airport is not the sole provider of ground handling services and competition with third party handlers or self-handling airlines exists, ground handling is separate from other activities of the airport. ${ }^{8}$

Next consider aviation and non-aviation activities of an airport. If non-aviation is important in terms of revenue, and complementarity of demand for non-aviation and aviation services is high, non-aviation and aviation may belong to a common airport market. However, in many cases the non-aviation sector of an airport will face a higher degree of competition with third parties, and the complementarity between aviation services and nonaviation services is rather weak. In this case it is more suitable to define separate markets for the aviation and non-aviation services.

Hub airports are unlikely to face competition with alternative modes of transportation (travel by car, train or ship) for a significant share of their passenger and cargo traffic, as longhaul traffic typically represents a substantial share of business for these gateways. Consequently it is not appropriate to consider the airport as part of a broadly defined transportation market. Even though air transportation may compete with other modes of transportation on certain routes (like the London-Paris route with competition from the Eurostar high speed train, or the Shinkansen train system for long distance travel within Japan), intermodal competition needs to restrain the pricing behavior of the whole airport to conclude that a more general transportation market definition is appropriate. If the airport is not able to pricediscriminate between the airlines depending on the route they serve, it is very unlikely that intermodal competition on some routes restricts the airport's pricing behavior with respect to all activities.

The definition of geographical markets. The definition of the geographical market determines the area in which airport competition potentially occurs. Generally, the definition of the geographic markets should be rather broad than narrow to avoid overestimating the extent of market power. For airports it rests on the analysis of catchment areas. Demand in the downstream transportation markets determines demand for the airport services. Demand is geographically linked to the region from which the airport attracts customers, and we define competitors as the airports geographically located in the same catchment area.

Passengers are usually willing to accept only a limited amount of inconvenience associated with reaching an airport. Further, different types of passengers attach different monetary values to this inconvenience. ${ }^{9}$ For a hub airport, it behooves to consider catchment areas for both origin-and-destination and transfer passengers. The catchment area tends to be smaller with regard to flights carrying O\&D passengers taking the airport as a startand endpoint for their journey, and broader for transit services, which utilize the hub-functionality of an airport. With respect to cargo, catchment areas tend to be very large; cargo transportation

${ }^{8}$ The ground handling directive of the European Union (European Commission, 1996) states that airports must allow for at least one competitor at any airport, and it is prohibited to limit self-handling activities of airlines. Some hub airports in the European Union like Amsterdam Airport Schiphol do not provide ground handling services at all (see also Airport Research Center, 2009).

${ }^{9}$ For instance, leisure travelers, being less time-sensitive, are willing to accept more discomfort to reach an airport as compared to the business travelers. Moreover, the catchment area for long-distance flights tends to be broader as compared to same for the short-distance journeys. 
is less time-sensitive, and number of stop-overs is of minor importance as compared to the passenger flights.

Large metropolitan areas, such as New York or London, are served by multiple airports. In this case it is a good starting point for the definition of the geographical markets to include at least all the city or metropolitan area airports in the market definition. This is appropriate even if some airports face congestion and may in fact not be available as alternatives, because the analysis of congestion belongs to the assessment of market power and is not conducted at the market definition stage. The same applies for airports in a catchment area under a common ownership structure. The market definition should then include all airports and prepare the way for the analysis of the ownership structure in the context of the assessment of market power.

\section{Factors affecting market power}

We should start this section by letting it be known to the reader that the following discussion assumes that an airport in question is run as a private profit-maximizing enterprise. In fact, a number of important airports worldwide are publicly owned and operated by local, regional, or national authorities. Market power is supposedly not a concern for such airports-the declared goal of public enterprises is to maximize social welfare rather than profit. ${ }^{10}$ Additionally, publicly run airports are often forced to operate within a rather rigid system of rules, restricting their freedom to set charges. For example, US Federal legislation stipulates that airports' aeronautical charges be sufficient to cover the costs; and expressly prohibit price discrimination. US airports are public enterprises. Further, studies of the managers' incentives in public enterprises suggest that managers are unlikely to behave as profit maximizers and have little incentive to engage in price discrimination.

\subsection{Switching costs}

Establishing presence at an airport is associated with fixed costs, some of which may be sunk. Further, leaving an airport to establish a base elsewhere entails switching costs. An airline's switching costs will likely be higher the larger its presence at an airport. This in particular means that the airport's captive customers will probably be the least likely ones to move out. At the same time, airports need their captive customers (usually those will be hub operators) as much as the captive customers need the airports. This, along with significant competition for transfer passengers between the airlines, can limit the airport's market power (see also Section 4.3). Also, concentrated hub airports are exposed to the airline-specific market risks. Consider Brussels International Airport (BRU), which has not as of now recovered after bankruptcy of Sabena in 2001. In 1999, BRU handled 20 million passengers, the volume in 2008 was 18 million. In 2002, the first full year after the bankruptcy of Sabena, Brussels airport handled only 14.4 million passengers (a 28 percent drop from 1999). In contrast, passenger volume at the nearby Amsterdam Airport Schiphol (which retained its status as hub for KLM) was 36.4 million in 1999, grew to 40.5 million in 2002 and reached 47.4 million in 2008.

If the airlines' demand is price elastic downstream (being more elastic the more competitive the market is), higher airfares reflecting higher aeronautical charges will yield lower traffic, potentially decreasing the airport's revenue. However, price

${ }^{10}$ In reality, public enterprises are often plagued by the principal-agent problems, leading to the operator setting different goals than social welfare maximization. We believe this is an important issue on its own right - however dealing with it in any detail would distract us from the focus of our study. 
responsiveness of the airlines' demand has to be very strong for this to happen. For instance, if aeronautical charges constitute 10 percent of airfare, a 10 percent increase in these charges, passed through to the customers by the airlines, will only produce a one percent higher airfares. For this increase in the airfare to produce a higher than 10 percent drop in traffic necessary to yield lower aeronautical revenue for the airport ${ }^{11}$, the absolute value of price elasticity of airlines' demand has to be at least 10 . While available estimates of the price elasticity for air travel rarely produce values higher than two (Gillen et al., 2003); individual airline's price elasticity of demand can be higher than this if the market is very competitive. Further, Forsyth (2001) indicated that the deadweight loss from the airport's market power will be small when aeronautical charges constitute a small percentage of airline costs. This distinction between price responsiveness of the aggregate demand for air travel and same for the individual airline's demand need to be clearly understood when performing the relevant investigation.

Thus from a regulator's perspective, the idea that airports are able to exert market power and increase prices is a good starting point for the assessment of market power in a specific case. Usually demand for air travel services downstream is sufficiently inelastic, which makes price increases profitable for the airport. This might however reverse, provided the airport relies on serving the airlines that face elastic travel demand. For instance, if the price increase at the airport asymmetrically affects single airlines which face strong competition (i.e. competition by other airlines or intermodal competition), or if the price increase mainly affects markets with high demand elasticity downstream (i.e. transfer markets or leisure travellers), it is more likely that airlines' individual demand elasticities are sufficiently large to make the increase of the airport charge unprofitable. Further, the airline may be unable to pass-on price increases to passengers, and higher airport charges might force airlines to exit the market in the long-run. This is more likely with small margins in the downstream transportation markets, or for financially constrained airlines. In this case, the regulator should be aware that long-run effects might reduce incentives to exercise market power, even if price increases were profitable from the airport's perspective in the short-run.

\subsection{Capacity and congestion}

Many important airports, in particular hubs, are capacity constrained and congested. Bottlenecks can be associated with slot availability, runway capacity, terminal capacity (i.e., departure gates), as well as noise restrictions. In either case, airports which are capacity constrained in one or the other way will have difficulty accommodating new airlines or expanded services by the incumbent carriers.

Relationship between constrained capacity and airport's market power is complex. On the one hand, an airport might leverage its position to charge more for access to both entrants and incumbents. On the other hand, captive users, having access to all the available aeronautical infrastructure, might try negotiating lower aeronautical charges, with the airport unable to attract entrants due to constrained capacity. Whether the airlines or the airport will have an upper hand in this situation depends on how easy it is for the airport to limit individual airlines' access to its infrastructure. From the practical perspective, contracts between the airport and the airlines need to be scrutinized. One must ask a simple question: 'If an airline is not using the resource, how easy is it for the airport to take the resource away and put it to an alternative use?'

\footnotetext{
${ }^{11}$ For the increase in price to produce lower total revenue, drop in the quantity (in percent) has to be higher than the percentage increase in price.
} 
The potential for the airport to withdraw or limit capacity to exercise its market and increase aeronautical charges can also be considered. While technically airport capacity is very difficult to adjust in the short-run; the airport managers can act strategically to decrease the airport's efficiency and effectively reduce the number of flights the airport is able to serve.

\subsection{Network effects}

An airport serving as a hub in a hub-and-spoke network will handle not only O\&D passengers, but also (and sometimes predominantly) transfer traffic. The following issues arise in this context. First, the hub operator might be the airport's captive customer. ${ }^{12}$ Second, the hub operator will generally face higher competition for transfer passenger as compared to O\&D passengers. This will imply that in response to higher aeronautical charges resulting in higher airfares, some of the passengers will switch to airports, which might not be located nearby (e.g., higher charges at London Heathrow may induce passengers to travel via Amsterdam or Frankfurt). The third issue is inter-related with the capacity constraints. While a hub airport may be congested, some of the gates and slots will effectively represent specific assets in a sense that the airport may not be able to find alternative users for its infrastructure in case its hub operator decides to leave.

As for the potential hub operators' countervailing power, an airline operating multiple hubs is more likely to have some leverage over the airport, as it can route its traffic via one or the other point in its network. Multi-hub airlines is more of a US than EU phenomenon. However, current consolidation on the European market might change this. For instance, Air France-KLM operates two hubs (Paris Charles de Gaulle and Amsterdam Airport Schiphol), and Lufthansa now has four hubs in its network (Frankfurt, Munich, Zurich, and Vienna). Hub operators may also have an upper hand in the airport-airline bargaining relationship if airport infrastructure (gates and/or slots) represents specific assets. Departure of a hub operator from such an airport will not be offset by increased operations of other incumbent carriers and/or new entrants. Moreover, a dehubbing event might lead to curtailment of services by the hub operator's partner airlines, as they are no longer able to feed connecting traffic to the hub airport.

\subsection{Intermodal competition}

The airlines' view is that it is rather difficult to compete with high-speed trains on routes where one can get from origin to destination in four hours or less (Müller et al., 2010). On a number of routes, development of high-speed rail has led to reduction or elimination of air services. The most vivid examples in the EU are Paris-Brussels, Paris-Lyon, and Madrid-Seville markets, where share of high-speed rail presently exceeds 75 percent. ${ }^{13}$ However, high-speed rail can enlarge the airport's catchment area and bring more origin and destination passengers to the airport. Even if the net effect of high speed rail is to increase the total number of passengers at an airport, it is not evident that such a development will increase the airport's revenue. The reason for this is that some of the passengers will be diverted from flights to trains (also reducing the number of flights and/or size of aircraft), and the airport will no longer be able to collect the related charges.

\footnotetext{
${ }^{12}$ Some airlines, even though they use an airport as a hub, will not be the airport's captive customers. Examples include AirTran in Atlanta and Frontier in Denver. At those airports, larger hub operators-Delta Air Lines and United Airlines, respectively-are the captive users.

${ }^{13}$ At the same time, air travel remains popular on the London-Paris market, despite the Eurostar providing fast and convenient service between the two cities.
} 
Analysis of the impact of intermodal competition might be either static or dynamic. In the static analysis, one would simply evaluate the airport's position relative to the transportation infrastructure, and analyze both which airline markets are exposed to intermodal competition, and how surface transport shapes the airport's catchment area. In a dynamic analysis, impact of changes in the transportation infrastructure will be evaluated. Planned and imminent changes to surface transportation infrastructure, which increase substitutability between air and surface car or train travel, will need to be identified and analyzed, at least qualitatively.

\section{Framework for the analysis of market power}

Overall, we have identified the following issues that need to be considered in the assessment of airport's market power for any defined market. First, airport's main customers (airlines) need to be identified. Then, one needs to determine whether any of these customers can be classified as captive users of the airport's infrastructure. Any airlines using the airport as their hub, as well as alliance partners of those airlines, need to be distinguished as well.

Afterwards, one has to take a careful look at the markets served by the airport's customers. The relevant catchment areas have to be identified. We have noted above that the airport's market power may be limited by competition among the airlines, as well as (and more importantly) by the possibility of the airlines leaving the airport and/or closing their hub. With this respect, the following issues need to be considered:

Overlap in destinations served by the current and the competing airports, separately for all defined markets.

Likelihood of hub closure by the hub operator(s). If such an event appears likely, it is important to evaluate the degree to which slots and gates held by the hub operator are specific assets.

Likelihood of non-hubbing airlines serving the area via an alternative airport.

Present and projected future competition between air travel and surface transportation.

Careful analysis of the airport-airline relationships is of crucial importance, especially for the congested airports. Here one needs to carefully examine the issue of control of critical resources (usually airport gates and take-off/landing slots). As we discussed above, control over the airport's resources will determine the airport's and the airlines' bargaining power in the congested airports.

Time dimension also appears important. Airlines' networks do not change overnight, mergers and bankruptcies in the airline industry may change the nature of competition, and surface infrastructure projects which could affect the airport several years from now might be considered or in progress at the time of evaluation.

\section{The effects of market power}

This section provides an overview of the various ways a hub airport could exercise its market power. We thus complement the empirical literature which examines determinants of airport charges, including the market characteristics upstream and downstream, the ownership structure or the regulatory regime (Bel and Fageda, 2010; Bilotkach et al., 2012; Van Dender, 2007). We draw from the general theory of pricing by the firms with market power to evaluate its applicability to the airport-airline relationships. 
Since at present time the vast majority of hub airports worldwide are regulated, the present section mostly speculates about the possible actions of hypothetical unregulated airports.

Three issues are important in this respect. First, facing demand from consumers which are heterogeneous in terms of their price sensitivity, a firm with market power can price discriminate. The extent and form of price discrimination crucially depends on the amount of information a firm obtains about its customers. Second, airports derive their revenue from both aviation and non-aviation services. The inter-dependence between the two sides of airport business may lead to cross-subsidization and affect airport charges. Third, as airport's customers are often not atomistic, bargaining between the airport and its customers is likely.

\subsection{Price discrimination}

Conventional wisdom suggests that left unregulated, an airport will most probably increase its aeronautical charges. This should especially be applicable to the cases where an airport is a local monopolist. Yet, price discrimination may mean that airport's individual customers may see their charges raise or fall.

Facing different customers and no restrictions on pricing, an airport could potentially price-discriminate. Moreover, as it should not be too difficult for the airport to obtain information about the airlines' business and ultimately their demand for the airport's services, we are most likely to see third-degree price discrimination in our setting. The following factors are likely to affect the nature and extend of price discrimination by the airports. First, the extent of the airline substitutability between the nearby airports will affect elasticity of the airlines' demand with respect to aeronautical charges. Second, and perhaps most importantly, the airport's ability to price-discriminate will depend on the traffic mix, both within and across the airlines. Third, capacity constraints will probably limit price discrimination, as the constrained airports will focus on the most profitable market segment, subject to this constraint. This is very well in line with a discriminating monopolist pricing out relatively few customers with low valuation, as accommodating them will limit the profit it can get from the less price sensitive market segments. Capacity constraints might contribute to the fact that such airports as Amsterdam, Madrid, and Munich set lower charges for transfer passengers as compared to the O\&D traffic, whereas London Heathrow does not offer such a differentiation in charges.

At the same time, we can expect congested airports to price discriminate in time dimension, setting higher charges at the expected peak travel times. This is somewhat contrary to the current practice of higher night-time charges observed at some major regulated airports. The regulators will most probably have to keep imposing these noise-based night-time charges on the otherwise unrestricted airports, as the airports will otherwise likely have very limited incentive to internalize the externality brought about by the night-time air traffic. Quite to the contrary, a rational unregulated airport will have an incentive to lower its night-time charges, to attract and raise revenue from less departure-time conscious leisure, charter, and cargo traffic. Here we have a classical negative externality problem requiring regulator's intervention.

\subsection{Cross-subsidization}

Airports derive their revenue from aviation and non-aviation activities (like parking and concessions). Importance of the latter has been growing, with some airports deriving about half of their revenue from the non-aviation services. ${ }^{14}$ Note that the airports

\footnotetext{
${ }^{14}$ See for instance, Bilotkach et al. (2012).
} 
are relatively unrestricted in their freedom to charge marketbased rates for non-aviation activities. Non-aviation activities are intertwined with the airport's aviation related operations in a peculiar way. On one hand, higher passenger traffic at an airport will necessarily imply more opportunities for concession revenue. On the other hand, higher parking prices will increase total cost of the trip for a passenger and may deter passengers from using the airport. These inter-dependencies create the opportunities for cross-subsidization between aviation and non-aviation sides of the airport business.

Under the single till regulation, aeronautical costs are subsidized with the non-aeronautical revenue. An airport free to set aeronautical charges and being a local monopolist, will choose aeronautical charges (e.g., per movement) in such a way that marginal revenue from the last aircraft movement is equal to the corresponding marginal cost of providing the services. Marginal revenue from the flight includes not only the aeronautical charges collected, but also marginal revenue from the non-aviation services, purchased by the passengers. From the airport's point of view, the extra non-aviation revenue is equivalent to a positive externality, which a deregulated profit-maximizing airport will internalize by reducing aeronautical charges to bring in the extra passengers and increase non-aviation revenue. Depending on how much non-aviation revenue is produced by an additional flight, the airport may even end up setting aeronautical charges below the corresponding marginal cost. Such cross-subsidization will be more likely when the airport either operates the non-aviation business itself, or shares profit with the operators of such businesses.

Taking the above considerations into account, we can suspect that an unregulated airport may choose to adopt a single-till like pricing structure-this issue should be appreciated when analyzing potential behavior of an unregulated airport. This also resonates with a currently developing view of airports as platforms in two-sided markets, bringing together airlines and passengers (Gillen, 2011). One of the results from the two-sided markets literature suggests that platforms may subsidize agents on either side of the market to increase the number of transactions.

\subsection{Bargaining}

Large concentrated airports are typically dominated by a hub operator, and such airports need their captive customers as much as the customers need the airports. With London Heathrow being probably the only exception, most currently large airports in Europe will lose a significant share of their traffic if the hub operator leaves or is forced into bankruptcy. Such a setup will necessitate some sort of bargaining between the concentrated airports and corresponding airlines.

Current literature has addressed relationship between airport dominance and airfares (Borenstein, 1989; Bilotkach, 2007), as well as between the airport concentration and air traffic delays (Brueckner, 2002; Mayer and Sinai, 2003). The apparent consensus from the above studies is that airlines with the dominant positions at airports will charge higher airfares. This increases the potential surplus that can be shared between the airlines and the airport. Also, empirical evidence indicates that the dominant airlines internalize some of the self-imposed congestion externalities.

In light of the above-stated, it is not obvious whether the airport or the airline will have a better bargaining position. This is especially true in case of an airline running a single-hub network. An air carrier with several hub airports in its network can utilize this network structure to its advantage, using a credible threat of routing some of the transfer traffic through another hub to negotiate lower aeronautical charges. It is not very difficult for an airline with multi-hub network to dismantle one of the smaller 
hubs-we have witnessed a number of such moves in the US airline industry over the last decade.

Few airlines within the EU, however, currently operate a dualhub system. In addition to the obvious consideration of the scale of operation required for the two- or multi-hub network to become a viable option, nationality clauses still present in bilateral agreements with some countries also get in the way. While there has been some progress towards removing this clause (e.g., US-EU Open Aviation Area agreement allows EU carriers to fly to the USA from other EU countries than their home state), it may take a number of years (if not decades) before nationality clauses become history.

In either case, it appears that the larger the carrier, the better its position in the airport-airline bargaining relationships. Size of the carrier's home country also matters, given the regulatory regime in international aviation. An important point to make here is that the latter consideration will remain important until a nationality clause is eradicated from bilateral air service agreements pretty much worldwide.

\section{Conclusions}

Airport industry is undergoing significant changes worldwide, as the airports are being increasingly viewed as businesses rather than infrastructure objects. Presumably, allowing more private sector involvement will bring about efficiency benefits to the airports. On the other hand, airports often have characteristics of local monopolies, and we might suspect that deregulated airports could exercise market power over their customers, the airlines. To make matters more intriguing, very few airports are operating as truly deregulated businesses, and none of the world's top airports is allowed to set its aeronautical charges as it sees fit. We thus do not have much empirical evidence on how deregulated airports would behave. This is especially true for the larger hub airports, as deregulation has mostly applied to smaller gateways.

Evaluation of an airport's market power is an issue of increasing importance. We actually find few cases where such an exercise has been implemented in practice. In this study, we provide an overview of the issues that are relevant to such an evaluation. Using the relevant economic concepts and showing how they relate to the specifics of airport business, we provide a general practical framework, which can be used for the airport market power assessment exercises.

The first issue to be considered is that of the definition of the relevant markets with respect to services and geography. Markets are separate from each other if substitution between different services is low, which restricts competitive pressure. The SSNIPTest is usually employed for market definition, shock tests or the analysis of price correlations may also be helpful. In practice, there is not yet a generally accepted market definition for airports, nor is there a history of cases which develop a common approach to this problem. The exercise of determining the market definition for airports has up to now been performed in only a handful of cases, and case law in the European or international context is rare. In the Amsterdam airport study (Müller et al., 2010), the definition of the relevant markets is broadly divided into two categories, which are the markets for the provision of infrastructure to airlines, and the markets for the access to the airport infrastructure for the provision of ground handling services by third parties. Both categories are further subdivided into several sub-markets. The UK Competition Commission defined a common market for all aeronautical services provided to the airlines and their ground handling agencies, and a separate market for commercial services provided at the airport (Competition Commission, 2009). 
Factors that affect airport's market power include the airlines' switching costs, airport capacity and congestion, network structure of the airport's main customers, and intermodal competition. To properly take these factors into account, we suggest the following assessment framework. First, airport's main customers need to be identified. Any airlines using the airport as their hub, as well as alliance partners of those airlines need to be distinguished as well. Second, one has to take a careful look at the markets served by the airport's customers. The relevant catchment areas have to be identified, which will guide towards identification of the competing airports. Then, one needs to carefully consider such issues as overlap in destinations served by the current and the competing airports, likelihood of hub closure by the hub operators, and present and projected future competition between air travel and surface transportation.

Careful analysis of the airport-airline relationships is of crucial importance, especially for congested airports. One needs to carefully examine the issue of control of critical resources (usually airport gates and take-off/landing slots). Control over the airport's resources will determine the airport's and the airlines' bargaining power in the congested airports.

An important conclusion stemming from our analysis is that an 'on the margin' analysis of responsiveness of the airport's aeronautical revenue to aeronautical charges will most likely lead to the conclusion that raising the charges will be profitable for the airport, as aeronautical charges constitute a small share of the total ticket price. The available estimates of price elasticity of air travel are not high enough to suggest that higher airport charges would produce substantial decrease in the number of airline passengers. At the same time, airlines' decisions to leave an airport and/or restructure their networks are not always made 'on the margin', and may not be dependent on the airport charges. We therefore believe that an analysis of the airport market power has to go beyond SSNIP-type tests, and involve an analysis of longer-term threats related to, among others, possible departure of key airlines and development of surface transport infrastructure.

The analysis of the likely effects of potential airport deregulation on charges the airport's customers will face is not a straightforward exercise. Even if an airport increases the level of its aeronautical charges following deregulation, its individual customers may see their charges either rise or fall. The effect of deregulation on prices faced by the airlines will depend on the following. First, the airport may decide to practice price discrimination, resulting in either higher or lower charges for individual airlines and their services. Second, bundling of aviation and related services will affect pricing. Third, the airport may change its policy with regard to cross-subsidization of aeronautical costs with nonaviation revenue. Fourth, individual airlines may be in a position to bargain for discounted charges.

\section{References}

Airport Research Center, 2009. Study on the Impact of Directive 96/67/EC on Ground Handling Services 1996-2007. Final Report.

Beckers, Thorsten, Jan P. Klatt, J. Kühling, 2010. Entgeltregulierung der deutschen Flughäfen. Reformbedarf aus ökonomischer und juristischer Sicht. Study commissioned by Bundesverband der Deutschen Fluggesellschaften e.V.

Germa, Bel, Xavier, Fageda, 2010. Privatization regulation and airport pricing: an empirical analysis for Europe. Journal of Regulatory Economics 37, 142-161, http://dx.doi.org/10.1007/s11149-009-9110-7.

Volodymyr, Bilotkach, 2007. Asymmetric regulation and airport dominance in international aviation: evidence from the London-New York market. Southern Economic Journal 74 (2), 505-523.

Volodymyr, Bilotkach, Clougherty, Joseph, Mueller, Juergen, Zhang, Anming, 2012. Regulation, privatization, and airport charges: panel data evidence from European airports. Journal of Regulatory Economics 42, 73-94.

Bishop, S., Walker, M., 2010. The Economics of EC Competition Law. Sweet \& Maxwell 
Severin, Borenstein, 1989. Hubs and high fares: dominance and market power in the U.S. airline industry. RAND Journal of Economics 20 (3), 344-365.

Brenkers, Randy, Verboven, Frank, 2007. Market Definition with Differentiated Products-Lessons from the Car Market. CESifo Seminar Series. MIT Press, Cambridge and London, pp. 153-186.

Brueckner, Jan K., 2002. Airport congestion when carriers have market power. American Economic Review 92, 1357-1375.

Civil Aviation Authority, 2010. Principles of Market Definition. Draft Working Paper.

Competition Commission, 2009. BAA Airports Market Investigation. March 2009.

Copenhagen Economics, 2012. Airport Competition in Europe. Study commissioned by ACI Europe.

Dobbs, I.M., 2006. Defining markets for ex ante regulation using the hypothetical monopoly test. International Journal of the Economics of Business 13 (1), 83-198.

European Commission, 1996. Council Directive 96/67/EC of 15 October 1996 on access to the groundhandling market at community airports. Official Journal L 272 25.10.1996, pp. 36-45.

European Commission, 1997. Case no COMP/M.786 Birmingham International Airport.

European Commission, 2004. Guidelines on the assessment of horizontal mergers under the council regulation on the control of concentrations between undertakings. Official Journal C 31 05.02.2004, pp. 5-18.

European Commission, 2005. Commission decision of 08.08.2005 referring case no COMP/M.3823-MAG/Ferrovial Aeropuertos/Exeter Airport to the competent authorities of the United Kingdom pursuant to Article 9 of Regulation (EC) No $139 / 2004$.

European Commission, 2006. Case no COMP/M.4164 Ferrovial/Quebec/GIC/BAA.

European Parliament, 2009. Directive 2009/12/EC of the European Parliament and of the council of 11 March 2009 on airport charges. Official Journal of the European Union L (70) (52), 11-16.

Peter, Forsyth, 2001. Promoting trade in airline services. Journal of Air Transport Management 7 (1), 43-50.

Forsyth, Peter, 2004. Replacing regulation: airport price monitoring in Australia. Monash U: Studies in Aviation Economics and Management. pp. 3-22.

Gaynor, Martin, Samuel, A. Kleiner, William, B. Vogt, 2011. A Structural Approach to Market Definition With an Application to the Hospital Industry. NBER Working Paper 16656.

Gillen, David, 2011. The evolution of airport ownership and governance. Journal of Air Transport Management 17 (1), 3-13.

Gillen, David, Morrison, W.G., Stewart, Stephen, 2003. Air Travel Demand Elasticities: Concepts, Issues and Measurement. Department of Finance, Government of Canada.

Graham, Anne, 2004. The Regulation of US Airports. U Westminster: Studies in Aviation Economics and Management. pp. 63-72.

International Competition Network, 2006. Merger Guidelines Workbook.

Ivaldi, Marc, Szabolcs, Lorincz, 2011. Implementing relevant market tests in antitrust policy: application to computer servers. Review of Law and Economics 7 (1).

Rui Cunha, Marques, Ana, Brochado, 2008. Airport regulation in Europe: Is there need for a European Observatory?. Transport Policy 15 (3), 163-172.

Christopher, Mayer, Todd, Sinai, 2003. Network effects, congestion externalities, and air traffic delays: or why not all delays are evil. American Economic Review 93, 1194-1215.

Müller, Jürgen, Volodymyr, Bilotkach, Frank Fichert, Hans-Martin, Niemeier, Erich Pels, Andreas Polk, 2010. The economic market power of Amsterdam Airport Schiphol, Study commissioned by the Netherlands Competition Authority (NMa).

Massimo, Motta, 2004. Competition policy: theory and practice. Cambridge University Press, New York, Melbourne.

Padilla Jorge, 2001. The role of supply-side substitution in the definition of the relevant market in merger control. A report for DG Enterprise A/4, European Commission.

US Department of Justice and Federal Trade Commission, 1997. Horizontal Merger Guidelines.

Van Dender, Kurt, 2007. Determinants of fares and operating revenues at US airports. Journal of Urban Economics 62 (2), 317-336. 